\title{
Genomic survey of the ectoparasitic mite Varroa destructor, a major pest of the honey bee Apis mellifera
}

\author{
R Scott Cornman', Michael C Schatz², J Spencer Johnston³, Yan-Ping Chen'1, Jeff Pettis', Greg Hunt', \\ Lanie Bourgeois ${ }^{5}$, Chris Elsik ${ }^{6}$, Denis Anderson ${ }^{7}$, Christina M Grozinger ${ }^{8}$, Jay D Evans ${ }^{1,4^{*}}$
}

\begin{abstract}
Background: The ectoparasitic mite Varroa destructor has emerged as the primary pest of domestic honey bees (Apis mellifera). Here we present an initial survey of the $V$. destructor genome carried out to advance our understanding of Varroa biology and to identify new avenues for mite control. This sequence survey provides immediate resources for molecular and population-genetic analyses of Varroa-Apis interactions and defines the challenges ahead for a comprehensive Varroa genome project.
\end{abstract}

Results: The genome size was estimated by flow cytometry to be $565 \mathrm{Mbp}$, larger than most sequenced insects but modest relative to some other Acari. Genomic DNA pooled from 1,000 mites was sequenced to $4.3 \times$ coverage with 454 pyrosequencing. The $2.4 \mathrm{Gbp}$ of sequencing reads were assembled into 184,094 contigs with an N50 of 2,262 bp, totaling $294 \mathrm{Mbp}$ of sequence after filtering. Genic sequences with homology to other eukaryotic genomes were identified on 13,031 of these contigs, totaling $31.3 \mathrm{Mbp}$. Alignment of protein sequence blocks conserved among $V$. destructor and four other arthropod genomes indicated a higher level of sequence divergence within this mite lineage relative to the tick Ixodes scapularis. A number of microbes potentially associated with $V$. destructor were identified in the sequence survey, including $\sim 300 \mathrm{Kbp}$ of sequence deriving from one or more bacterial species of the Actinomycetales. The presence of this bacterium was confirmed in individual mites by PCR assay, but varied significantly by age and sex of mites. Fragments of a novel virus related to the Baculoviridae were also identified in the survey. The rate of single nucleotide polymorphisms (SNPs) in the pooled mites was estimated to be $6.2 \times 10^{-5}$ per bp, a low rate consistent with the historical demography and life history of the species.

Conclusions: This survey has provided general tools for the research community and novel directions for investigating the biology and control of Varroa mites. Ongoing development of Varroa genomic resources will be a boon for comparative genomics of under-represented arthropods, and will further enhance the honey bee and its associated pathogens as a model system for studying host-pathogen interactions.

\section{Background}

Honey bees (Apis mellifera) are an important agricultural commodity providing honey, other bee products, and pollination services [1,2]. Domesticated honey bees in the United States and elsewhere have been in decline in recent years, despite an increasing need for honey bee pollination services [3]. This fact is often blamed on

\footnotetext{
* Correspondence: Jay.Evans@ars.usda.gov

'USDA-ARS, Bee Research Laboratory, 10300 Baltimore Ave., Beltsville, MD 20705 USA

Full list of author information is available at the end of the article
}

increasing challenges from pests and pathogens, as well as episodes of severe decline such as the enigmatic 'colony collapse disorder' (CCD) [4].

Among the most detrimental of honey bee pests is the ectoparasitic mite Varroa destructor [5]. V. destructor and its closely related congener, $V$. jacobsoni, are native to Asia where they parasitize the Eastern honey bee, A. cerana. $V$. destructor was only identified as a morphologically and genetically distinct species from $V$. jacobsoni relatively recently [6]. $V$. destructor began to appear in Asian colonies of $A$. mellifera during the last century and is now
C Biomed Central 
widely distributed, inadvertently aided by trade in bees and bee products.

Mite-infested bee colonies suffer directly from parasitism of pupae and adults, and indirectly from viral and microbial pathogens that the mites vector $[7,8]$. Feeding by mites induces an immunosupression in bees that leads to increased titres of pre-existing infections [9], further compounding their impact. The economic toll of $V$. destructor on apiculture is estimated to be millions of U.S. dollars per year, and chemical control agents are worrisome both for their collateral effects on bee health and the potential for honey contamination [10].

Varroa-honey bee interactions are mediated to a large extent via chemical cues, and bees have numerous mechanisms to control Varroa populations (reviewed in $[5,11])$. Varroa mites reproduce on honey bee pupae, using chemical signals produced by the developing honey bee larvae to target appropriately aged hosts. The mature female offspring of reproductive Varroa emerge with the adult honey bee, and subsequently move to nurse bees (which are engaged in brood care), thereby allowing them to remain in close proximity to the brood $[12,13]$. Honey bees resist 'Varroatosis', the infestation of colonies by Varroa mites, via grooming of adult infested bees, removal of infested pupae (hygienic behavior), and physiological resistance mechanisms [5]. Recent successes in breeding Varroa-resistant bees, including the selection of 'Russian' bees with longstanding exposure to mites $[14,15]$, indicate that a better understanding of how bees and mites interact with each other can lead to novel management strategies.

Comparative studies of the fragility of the A. mellifera $V$. destructor interaction, which has apparently prevented most Asian lineages of $V$. destructor as well as other Varroa species from colonizing A. mellifera [6,16-18], supports the hypothesis that mite olfaction or other requirements for mite reproduction may be suitable control targets. A molecular-genetic approach to develop such innovative controls would clearly benefit from further insights into Varroa genomics, which could be exploited in conjunction with tools already extant for honey bee. Prior to this study, genes for only two nonmitochondrial $V$. destructor proteins had been deposited in GenBank, a sodium channel gene (AAN37408.1) and a glycoprotein (ACU30143.1). Genome sequencing will greatly expand this gene catalog, and may also uncover unforeseen targets for novel and specific acaricides, such as divergence in metabolic pathways between mites and bees or the discovery of important microbial interactions.

High-throughput, shotgun sequencing of whole genomes allows the rapid identification of thousands of genic sequences, greatly facilitating molecular and population-genetic studies that would otherwise proceed in piecemeal and laborious fashion. Here we report an initial sequence survey of the $V$. destructor genome in conjunction with a flow-cytometric estimate of genome size. Our annotations and analysis should aid investigators seeking molecular approaches to mite control. They will also provide a guide for a planned full genome project for this species [19], one of several genomics initiatives that are unfolding the molecular interactions between honey bees and a constellation of potentially interacting pathogens $[4,7,20,21]$.

Of the eight genetically distinct lineages of $V$. destructor that parasitize A. cerana in Asia, two have been identified on A. mellifera $[6,18,22,23]$. Anderson [24] designated these lineages the Japan (J) and Korea (K) 'haplotypes' in reference to mitochondrial DNA makers, but they are concordantly distinct at nuclear markers as well [23]. Genetic differentiation within lineages is low [23], likely reflecting the population-genetic impact of life-history traits [5] such as full-sib mating and male haploidy [25], as well as potential population bottlenecks tied to host-shift events and subsequent range expansion $[18,23]$. In this study, we have analyzed the K haplotype of $V$. destructor from A. mellifera, the predominant haplotype presently found in North America [23]. We have identified over 13,000 contigs with sequences homologous to other species; many of these have recognized domains and/or functional annotations transferred from other arthropods. Interestingly, $V$. destructor appears to have experienced a higher rate of protein evolution than Ixodes scapularis since their divergence from the most recent common ancestor over 300 million years ago. Sequences attributable to a range of microbes were identified, including a large number of sequences from one or more novel actinomycete bacteria, the presence of which was confirmed by PCR in individual mites but not in adult honey bees. We also identified a novel virus related to the Baculoviridae that was abundant in the genomic survey. Finally, we found a low level of nucleotide polymorphism in the sequenced sample of $\sim 1,000$ mites, consistent with expectation [23]. This bodes well for future efforts to sequence and assemble a reference genome for this species and to identify genetic variation that correlates with host-interaction traits among Varroa strains and species.

\section{Results}

\section{Genome size}

Flow cytometry of $V$. destructor nuclei (normalized to nuclei of Drosophila virilis) yielded a haploid genome size estimate of $565 \pm 3 \mathrm{Mbp}$ (Figure 1). This genome size is larger than that of many insects but substantially smaller than that of numerous mites and ticks for which genome projects are underway or have been proposed (> 2,000 Mbp, [26]. It is also lower than the general range for ticks, which spans from roughly 1,000 Mbp in 


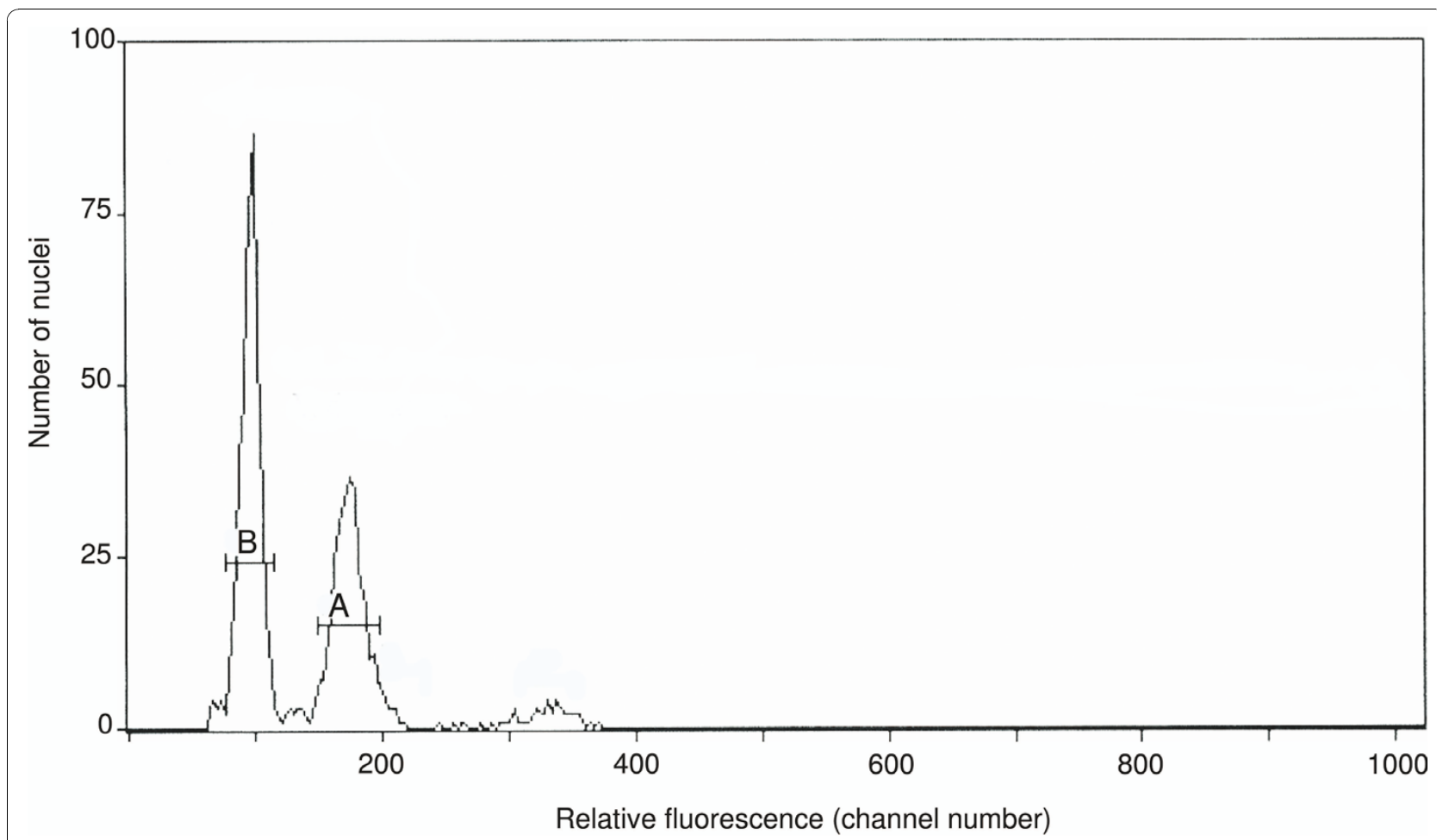

Figure $12 \mathrm{C}$ genome size estimate for Varroa destructor. $2 \mathrm{C}$ genome size estimate for $V$. destructor based on flow cytometry, normalized to the Drosophila virilis genome (A). The $V$. destructor fluorescence peak (B) corresponds to a genome size of 0.577 picograms or $565 \pm 3 \mathrm{Mbp}$.

the argasid soft tick Ornithodoros turicata to $3,100 \mathrm{Mb}$ in the ixodid hard tick Amblyomma americanum [27]. However, examples of very small acarid genomes are known. Most notably, the two-spotted spider mite Tetranychus urticae, which has been advocated as a model for genetic and developmental studies of chelicerates [28]), has an estimated genome size of only $75 \mathrm{Mbp}$. It is not yet clear to what extent these large differences in genome size are driven by variation in gene content, repetitive fraction, and/or ploidy. While the contributions of the latter two factors have been frequently noted, the potential contribution of gene expansion has been highlighted by recent analyses of waterflea [29] and pea aphid [30] that reveal a roughly two-fold increase in gene content relative to other arthropods.

\section{Sequencing, assembly, and filtering}

Six pyrosequencing runs on a Genome Sequencer FLX instrument (454 Life Sciences) produced 2.4 Gbp of unpaired sequencing reads. After trimming low quality sequence, the average read length was $365 \mathrm{bp}$, generating an expected genome coverage of $4.2 \times$. The reads were then assembled into contigs with the CABOG package of Celera Assembler version 5.2 [31]. The resulting assembly had a realized median contig coverage of $4.3 \times$, but was highly fragmented and summed to only $318 \mathrm{Mbp}$ of sequence, substantially less than the estimated genome size of $565 \mathrm{Mbp}$. Table 1 provides statistics for this assembly before and after removing problematic or undesired sequences (detailed below). The modest contig lengths are primarily a consequence of low coverage, as over $97 \%$ of contigs greater than 1 Kbp terminate due to coverage gaps rather than ambiguity from repetitive sequences. In fact, contig lengths were comparable to that expected $(\sim 3,860 \mathrm{bp})$ for an idealized assembly of equivalent coverage and read length, following the method of [32].

As detailed in the Methods, the small physical size of $V$. destructor required the collection of large numbers of

Table 1 Statistics of the Varroa destructor genome sequence survey

\begin{tabular}{lll}
\hline Statistic & Initial assembly & Filtered assembly \\
\hline Number of contigs & 271,543 & 184,094 \\
\hline Sum of contig length (Mbp) & 318 & 294 \\
\hline Maximum contig length (bp) & 18,703 & 16,332 \\
\hline Mean contig length (bp) & $1,170.4$ & $1,597.5$ \\
\hline N50 contig length (bp) & 2,107 & 2,262 \\
\hline Contigs $\geq 1,000$ bp & 107,195 & 105,621 \\
\hline Contigs $\geq 5,000$ bp & 5,407 & 5,374 \\
\hline Contigs $\geq 10,000$ bp & 120 & 118 \\
\hline Mean coverage & 4.3 & 5.0 \\
\hline
\end{tabular}


mites from multiple honey bee colonies in order to obtain sufficient DNA for this survey. While mites were carefully cleaned and examined under a dissection microscope to remove any non-target organisms that might have been collected inadvertently, whole-organism extractions necessarily entail the possible inclusion of associated microbes, particularly gut microbes. The gut flora may include symbiotic, commensal, and pathogenic prokaryotes and eukaryotes, which are often important components of the ecology of arthropod species. We therefore filtered the assembled contigs based on $\mathrm{G}+\mathrm{C}$ content, coverage, and sequence homology, in order to minimize the mis-annotation of microbial sequences as $V$. destructor, as well as to identify novel microbes of interest. Comparable strategies have been successfully applied to the classification of metagenomic samples (e.g., [33]).

We first examined the distribution of contig-mean coverage versus length (Figure 2), which revealed relatively few outliers, and these were found to be enriched in mitochondrial and ribosomal sequences. Thus, the vast majority of the assembled contigs do not appear to contain many collapsed nuclear repeats. Based on the observed median and variance of coverage (Figure 2), we excluded contigs with less than $2 \times$ coverage and greater than $10 \times$ coverage, as well as contigs less than $300 \mathrm{bp}$ in length, from the analyzed $V$. destructor assembly.

We then examined $\mathrm{G}+\mathrm{C}$ content of contigs (Figure 3), which suggested that Varroa nuclear DNA falls largely between $32-58 \% \mathrm{G}+\mathrm{C}$ content (40.9\% $\mathrm{G}+\mathrm{C}$ on average). Contigs with lower $\mathrm{G}+\mathrm{C}$ content and higher coverage showed strong homology to mitochondrial and ribosomal DNA sequences previously reported for $V$. destructor, as would be expected. Contigs with higher $\mathrm{G}+\mathrm{C}$ consistently showed higher sequence similarity to bacterial sequences than to arthropod sequences. For example, Figure 4 illustrates the distribution of contigs with BLASTX matches to the high $\mathrm{G}+\mathrm{C}$ bacterial order Actinomycetales at an expectation of $10^{-8}$, plotted as a function of length and $\mathrm{G}+\mathrm{C}$ content of contigs. Of these contigs, only those above approximately $58 \% \mathrm{G}+\mathrm{C}$ content were better matches (by sequence similarity and E-value) to Actinomycetales than to arthropods, or lacked an arthropod match entirely. Based on these considerations, we removed contigs outside the range of

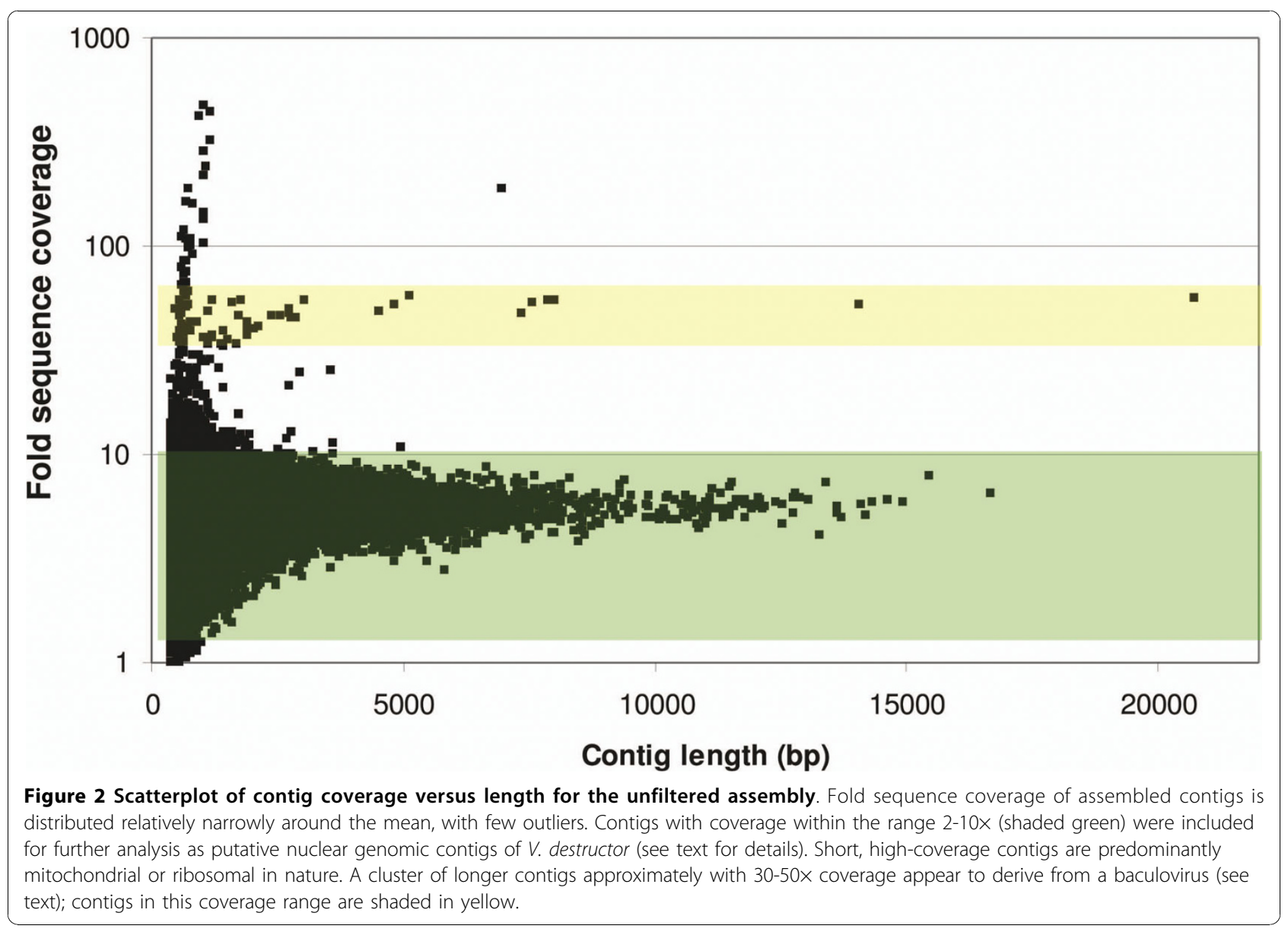




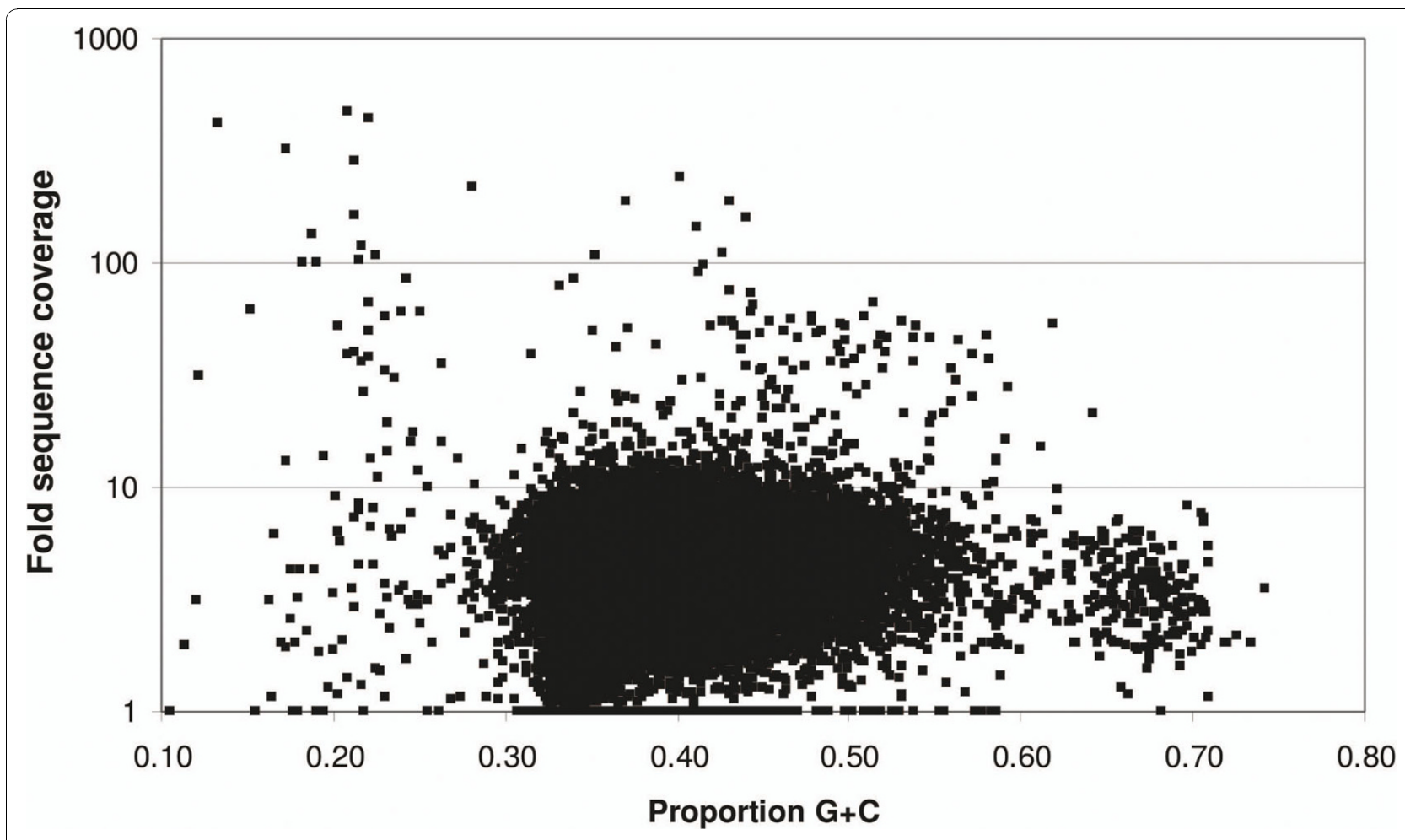

Figure 3 Scatterplot of contig $\mathbf{G}+\mathbf{C}$ content versus coverage. Scatterplot of contig $\mathrm{G}+\mathrm{C}$ content versus fold sequence coverage shows a clear mode of $\mathrm{G}+\mathrm{C}$ content in the range of $32-56 \%$. The long tail of low $\mathrm{G}+\mathrm{C}$ contigs includes low-complexity sequences such as AT repeats, as well as mitochondrial and ribosomal contigs. A secondary mode of high $\mathrm{G}+\mathrm{C}$ contigs is also apparent; these contigs include many BLAST matches to the bacterial order Actinomycetales (see text).

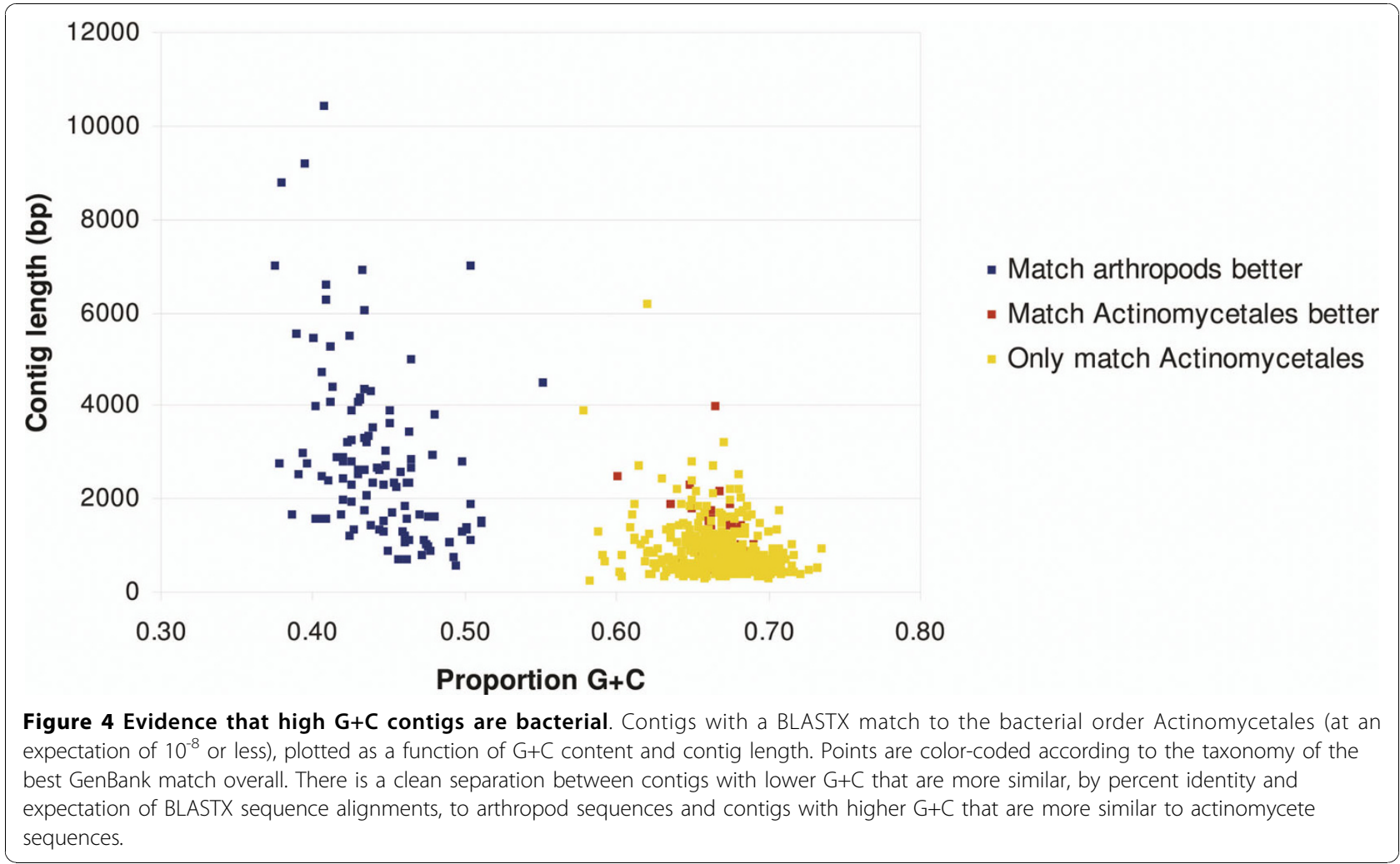


$32-58 \% \mathrm{G}+\mathrm{C}$ from the analyzed $V$. destructor assembly unless they contained a superior match to a eukaryotic sequence in GenBank at an expectation of $10^{-8}$. Additional filtering was performed as described in the Methods to specifically remove sequences from organisms that were considered potential contaminants a priori, such as known microbial pathogens of honey bees that are dispersed as spores.

\section{Actinomycete discovery}

The strong secondary mode of high $\mathrm{G}+\mathrm{C}$ contigs in Figure 3 and taxonomically coherent BLAST hits (Figure 4) suggests that one or more Actinomycete species were particularly abundant in the sequenced sample. Together these contigs totaled $\sim 300 \mathrm{Kbp}$ of sequence, which were further analyzed with the BLAST2GO annotation tool [34]. Additional file 1 includes BLAST2GO output that summarizes the distribution of BLASTX hits among these contigs with respect to matched species, expectation, and sequence similarity. All of the most frequently matched organisms are members of Actinomycetales. Ribosomal sequences were also found that had strong similarity to this clade, the closest match ( $98 \%$ identity) being to the genus Segniliparus.

To further investigate the distribution of this bacterium in Varroa mites, we designed primers specific to a homolog of translation initiation factor TIF-3. These primers amplified the target sequence from DNA of individual mites, as confirmed by sequencing of the amplicon. The rate of infection in a sample of mites (see Methods) is shown in Table 2. Rates of infection varied significantly $(\mathrm{P}<0.01, \chi 2$ test) by age and sex. Mature females were infected more often than males (61\% versus $33 \%)$. We did not detect the infection in a small sample of eggs and it was rare in nymphs (11\%). These data suggest that horizontal transmission of the bacteria occurs within capped cells (from which males do not leave). We were not able to amplify the target from $A$. mellifera DNA extracted from adult bee abdomens, either with these primers or another pair targeting an $\mathrm{ABC}$ transporter gene (see Methods). Given the

\section{Table 2 Frequency of infection of individual mites by a novel actinomycete bacterium identified in the V. destructor sequence survey}

\begin{tabular}{lll}
\hline Class & Present & Absent \\
\hline Male & 4 & 8 \\
\hline Female & 11 & 7 \\
\hline Nymph & 2 & 16 \\
\hline Egg & 0 & 5
\end{tabular}

Presence or absence of the bacterium is based on a PCR assay (see text for details). intimacy of Varroa mites with their hosts, this result suggests that the bacterium has some specificity to Varroa. While additional surveys at broader geographical scales are needed to confirm and extend these conclusions, the amount of sequence classified as actinomycete is remarkable given that common microbial components of the arthropod gut flora [35] (e.g., the Enterobacteriaceae) were not strongly evident in the initial assembly (see Methods). However, as the mites were not surface sterilized prior to extraction of genomic DNA, it is unclear whether the infection is topical or internal.

\section{Baculovirus discovery}

Curiously, the longest contig in the initial assembly was among those filtered due to high coverage across its entire length (a mean of $56 \times$ ). In fact, this contig is part of a distinct group visible in Figure 2 that have mean coverage around $50 \times$, sloping down to $\sim 30 \times$ as contig length decreases (a frequently observed phenomenon attributable to low-coverage at contig ends). We therefore investigated whether contigs $\geq 1 \mathrm{Kbp}$ in length and with 30-60× coverage were of a consistent type, such as microbial DNA or a class of repetitive sequence (e.g., ribosomal genes or transposable elements). BLASTX and Pfam [36] searches indicated that these high coverage contigs derive from a novel baculovirus. Baculoviruses are large DNA viruses that are common in certain arthropod taxa and often have strong impacts on host survival (reviewed by [37]). Known baculoviruses range from 80 to $180 \mathrm{~kb}$ in length and typically encode more than 100 ORFs, some of which are putatively specific to Baculoviridae. Indeed, several baculovirusspecific domains were detected among the 216 methionine-initiated ORFs greater than 90 amino-acids in length that were found on these high-coverage contigs (Table 3). Domains related to viral genome replication as well as other domains previously reported in Baculoviridae were also found. The baculovirus Spodoptera litura NPV appears to be the most similar viral species overall in GenBank, as there were strong matches to ribonucleotide reductase subunits RR1 and RR2 and weaker matches to a number of other peptides of this viral species. A number of ORFs encoding low-complexity proteins were identified from these high-coverage contigs, but it remains unclear which of these, if any, are viral in nature (all filtered contigs and predicted ORFs are given in Additional file 2). PCR primers specific to two separate loci (see Methods) confirmed the presence of these sequences in the original sample pool, but we were able to amplify these loci from only two of fifty individual mites collected at different times from the same colonies as the sequenced sample. Thus, the putative baculovirus-like sequences do not appear to be common in $V$. destructor, although we can infer from 
Table 3 Evidence for a novel virus related to the Baculoviridae in the sequenced sample of Varroa destructor

\begin{tabular}{|c|c|c|c|}
\hline ORF & Pfam domain description & Expectation & Reported in Baculoviridae? \\
\hline VDK00007920-4466_1 & Ribonucleotide reductase, barrel domain & $5.50 \mathrm{E}-231$ & Yes \\
\hline VDK00121146-847_1 & Ribonucleotide reductase, small chain & $1.30 \mathrm{E}-125$ & Yes \\
\hline VDK00001240-6963_1 & Thymidylate synthase & 3.60E-114 & Yes \\
\hline VDK00008686-4345_1 & Kinesin motor domain & $3.90 \mathrm{E}-060$ & $\mathrm{No}^{*}$ \\
\hline VDK00103915-1040_1 & Reverse transcriptase & 7.80E-035 & Yes \\
\hline VDK00064516-1660_1 & BRO family, $\mathrm{N}$-terminal domain & $1.60 \mathrm{E}-017$ & Yes \\
\hline VDK00001041-7192_1 & Chitin binding domain & $1.50 \mathrm{E}-010$ & Yes \\
\hline VDK00192648-381_1 & Pacifastin inhibitor (LCMII) & 3.60E-008 & No \\
\hline VDK00158309-530_2 & Baculovirus hypothetical protein & $1.10 \mathrm{E}-006$ & Yes \\
\hline VDK00025611-2890_1 & Matrixin (matrix metalloprotease) & 3.80E-006 & Yes \\
\hline VDK00139482-672_1 & Protein of unknown function (DUF666) & $3.90 \mathrm{E}-006$ & Yes \\
\hline VDK00179897-428_1 & Phosphatidylinositol-specific phospolipase & 5.60E-006 & $\mathrm{No}^{*}$ \\
\hline VDK00008449-4382_2 & Protein of unknown function (DUF686) & $9.90 \mathrm{E}-006$ & Yes \\
\hline VDK00099267-1099_1 & Zinc knuckle (retroviral gag protein) & $1.20 \mathrm{E}-004$ & Yes \\
\hline VDK00107278-999_1 & Baculovirus BRO family, $\mathrm{N}$-terminal domain & 1.80E-004 & Yes \\
\hline VDK00158309-530_3 & Gamma-glutamyltranspeptidase & $2.60 \mathrm{E}-004$ & $\mathrm{No}^{*}$ \\
\hline VDK00071395-1528_1 & Collagen triple helix repeat & $8.20 \mathrm{E}-004$ & $\mathrm{No}^{*}$ \\
\hline VDK00038309-2357_1 & Collagen triple helix repeat & $9.20 \mathrm{E}-004$ & $\mathrm{No}^{*}$ \\
\hline VDK00202991-345_3 & Amelogenin (cell adhesion protein) & $2.20 \mathrm{E}-003$ & No \\
\hline VDK00042225-2226_1 & Alpha/beta hydrolase fold & $2.40 \mathrm{E}-003$ & $\mathrm{No}^{*}$ \\
\hline VDK00021332-3129_1 & Phage integrase family & $3.00 \mathrm{E}-003$ & $\mathrm{No}^{*}$ \\
\hline VDK00104983-1027_1 & Collagen triple helix repeat & 4.20E-003 & $\mathrm{No}^{*}$ \\
\hline VDK00202991-345_2 & Collagen triple helix repeat & 4.20E-003 & $\mathrm{No}^{*}$ \\
\hline VDK00043167-2196_3 & Protein of unknown function (DUF686) & $9.10 \mathrm{E}-003$ & Yes \\
\hline VDK00073176-1494_3 & Gamma-glutamyltranspeptidase & $9.20 \mathrm{E}-003$ & $\mathrm{No}^{*}$ \\
\hline VDK00048355-2046_1 & Matrixin (matrix metalloprotease) & 0.01 & Yes \\
\hline
\end{tabular}

Pfam matches are shown for methionine-initiated ORFs of 90 amino acids or more that were encoded by contigs at least $1 \mathrm{~kb}$ in length and with 30x-60x coverage. Collectively the matches are consistent with a viral origin and include several domains characteristic of Baculoviridae. Only matches with an expectation of 0.01 or less are shown. *Domain reported from at least one virus in Pfam [36] and Interpro [66] databases. **Present in one baculovirus accession (Q65353 of UniProt [67]) due to a retrotransposon insertion.

their high coverage in the initial assembly that high titres are sometimes achieved. This result also demonstrates that these sequences are not integrated into the $V$. destructor genome. Because baculoviruses are important tools for arthropod transgenics and biocontrol $[38,39]$, efforts to clarify the nature of this virus and its hosts are underway.

\section{V. destructor annotation and evolutionary comparison with other arthropods}

We used BLASTX (for genomic contigs) and BLASTP (for ORFs of 90 residues or more) to identify genic sequences in the assembly. Sequences were initially searched against a database of five arthropod peptide predictions (Drosophila melanogaster, Anopheles gambiae, Pediculus humanus [a representative non-Dipteran insect], Daphnia pulex, and I. scapularis), with a minimum expectation of $10^{-8}$, and then secondarily against the eukaryotic Refseq database at the same expectation. In total, 13,031 contigs were identified with BLASTdetected similarity to database sequences (listed in Additional file 3). These contigs had a median length of $1,967 \mathrm{bp}$ and summed to $31.3 \mathrm{Mbp}$, and represent roughly $10 \%$ of the total assembled sequence (294 Mbp after filtering). ORFs with significant Pfam domains are listed in Additional file 4 and the sequences are provided in Additional file 5.

These annotated gene fragments are necessarily an incomplete accounting of the number and type of genes in $V$. destructor, given the limitations of the assembly and lack of transcriptome data. Additional genomic resources are needed for robust gene models and are in development [19]. However, we used two approaches to infer how well represented Varroa protein-coding genes are in this survey. We first identified ORFs that were putatively homologous to enzymes of the glycolysis/ 
gluconeogenesis pathway, using KEGG-annotated pathway components [40] from the mosquito, Anopheles gambiae, and the tick, I. scapularis, as BLAST queries. I. scapularis is the most closely related organism to $V$. destructor for which an extensively annotated genome sequence exists [41]. We identified 19 putative pathway components in our search (Table 4), whereas there are 21 members in I. scapularis and 23 in A. gambiae. A second, similar approach to assessing how well $V$. destructor genes were represented in the assembly was to query all predicted ORFs against the CEGMA set of hidden Markov models of evolutionarily conserved proteins [42]. A Hmmer [43] search found matches for 303 of the 458 protein models available, at an E-value threshold of 1.0 (matches at this level also had BLASTP matches in GenBank with E-values less than $10^{-10}$ ). The same search performed on I. scapularis predicted proteins found matches for 429 models. Given that ORFs are proxies for single coding exons, both approaches used here are likely to under-sample $V$. destructor coding sequences. These comparisons nonetheless suggest that a majority of the coding potential of $V$. destructor was captured in this survey, if in fragmented form. However, they also indicate that comparisons of genefamily or protein-domain abundance in $V$. destructor relative to other arthropods may be premature.

We used RepeatMasker [44] to characterize the distribution of protein-coding transposable element classes in $V$. destructor, which are summarized in Table 5. The Mariner class of DNA transposon was by far the most abundant transposable element identified. Some retrotransposons were also common, particularly gypsy-type

Table 4 The Varroa destructor glycolysis/gluconeogenesis pathway is well represented in the genome sequence survey

\begin{tabular}{|c|c|c|c|c|c|c|c|c|}
\hline $\begin{array}{l}\text { Glycolysis/gluconeogesis } \\
\text { enzyme }\end{array}$ & $\begin{array}{l}\text { KEGG } \\
\text { ID }\end{array}$ & $\begin{array}{l}\text { Annotated in } \\
\text { A. gambiae }\end{array}$ & $\begin{array}{l}\text { Annotated in } \\
\text { l. scapularis }\end{array}$ & $\begin{array}{l}\text { Closest contig match in the } V \text {. } \\
\text { destructor assembly (BLASTX) }\end{array}$ & Strand & Start & Stop & E-value \\
\hline 6-phosphofructokinase & K00850 & $x$ & $x$ & VDK00166959 & + & 274 & 486 & $6.00 \mathrm{E}-027$ \\
\hline acetyl-CoA synthetase & K01895 & $x$ & $x$ & VDK00052872 & - & 313 & 1554 & $3.00 \mathrm{E}-085$ \\
\hline aldehyde dehydrogenase & K00128 & $x$ & $x$ & VDK00013090 & + & 2385 & 3224 & $1.00 \mathrm{E}-138$ \\
\hline $\begin{array}{l}\text { dihydrolipoamide } \\
\text { dehydrogenase }\end{array}$ & K00382 & $x$ & $x$ & VDK00011534 & - & 343 & 917 & $1.00 \mathrm{E}-020$ \\
\hline enolase & K01689 & $x$ & $x$ & VDK00029529 & - & 752 & 2211 & $7.00 \mathrm{E}-143$ \\
\hline fructose-1,6-bisphosphatase & K03841 & $x$ & $x$ & VDK00132162 & + & 158 & 355 & 1.00E-023 \\
\hline fructose-bisphosphate aldolase & K01623 & $x$ & $x$ & VDK00012888 & + & 801 & 2121 & $1.00 \mathrm{E}-073$ \\
\hline glucose-6-phosphate isomerise & K01810 & $x$ & $x$ & VDK00034893 & + & 2 & 145 & $6.00 \mathrm{E}-018$ \\
\hline $\begin{array}{l}\text { glyceraldehyde 3-phosphate } \\
\text { dehydrogenase }\end{array}$ & K00134 & $x$ & $x$ & VDK00020468 & - & 142 & 2477 & $2.00 \mathrm{E}-077$ \\
\hline hexokinase & K00844 & $x$ & $x$ & VDK00023511 & - & 313 & 1522 & $2.00 \mathrm{E}-094$ \\
\hline $\begin{array}{l}\text { phosphoenolpyruvate } \\
\text { carboxykinase }\end{array}$ & K01596 & $x$ & $x$ & VDK00063370 & - & 1166 & 1684 & $1.00 \mathrm{E}-038$ \\
\hline phosphoglucomutase & K01835 & $x$ & $x$ & VDK00033184 & - & 236 & 478 & 3.00E-024 \\
\hline phosphoglycerate kinase & K00927 & $x$ & $x$ & VDK00052433 & + & 351 & 1229 & 4.00E-032 \\
\hline phosphoglycerate mutase & K01834 & $x$ & $x$ & VDK00033074 & - & 257 & 2550 & $5.00 \mathrm{E}-031$ \\
\hline $\begin{array}{l}\text { pyruvate dehydrogenase E1 } \\
\text { component, subunit alpha }\end{array}$ & K00161 & $x$ & $x$ & VDK00079694 & - & 2 & 1382 & $8.00 \mathrm{E}-043$ \\
\hline $\begin{array}{l}\text { pyruvate dehydrogenase E1 } \\
\text { component, subunit beta }\end{array}$ & K00162 & $x$ & $x$ & VDK00041927 & - & 527 & 2110 & 2.00E-020 \\
\hline $\begin{array}{l}\text { pyruvate dehydrogenase E2 } \\
\text { component }\end{array}$ & K00627 & $x$ & $x$ & VDK00062508 & - & 165 & 416 & 4.00E-033 \\
\hline pyruvate kinase & K00873 & $x$ & $x$ & VDK00096436 & - & 676 & 1131 & 4.00E-067 \\
\hline $\begin{array}{l}\text { S-(hydroxymethyl)glutathione } \\
\text { dehydrogenase }\end{array}$ & K00121 & $x$ & $x$ & VDK00003663 & - & 1731 & 2700 & 4.00E-125 \\
\hline $\begin{array}{l}\text { glucose-6-phosphate 1- } \\
\text { epimerase }\end{array}$ & K01792 & $x$ & $x$ & & & & & \\
\hline triosephosphate isomerise & K01803 & $x$ & $x$ & & & & & \\
\hline aldose 1-epimerase & K01785 & $x$ & & & & & & \\
\hline L-lactate dehydrogenase & K00016 & $x$ & & & & & & \\
\hline
\end{tabular}

Putative pathway components listed below were identified by BLASTX, using KEGG-annotated components [40] from Anopheles gambiae and Ixodes scapularis as search queries. 
long-terminal-repeat (LTR) retrotransposons and LINEs (long interspersed nuclear elements). Helitrons, which replicate by a rolling-circle method, were also numerous. Given the quasi-clonal nature of the $\mathrm{K}$ and $\mathrm{J}$ haplotypes of $V$. destructor[23], comparative re-sequencing of these two groups could uncover recently active transposable elements. Active elements are of interest because they are important contributors to genome evolution, including the creation of novel host genes [45], and have utility for functional genomics [46].

Although the I. scapularis genome should be a valuable guide for homology-based gene prediction in $V$. destructor, these lineages are estimated to have diverged $336 \pm 26$ million years ago [47]. It is therefore of interest to assess the level of sequence divergence between these two taxa, as well as the divergence of these Acari from other model arthropods. We identified 730 peptide blocks, averaging 128 residues in length, that were conserved between putative orthologs in these two species and among their closest homologs in Da. pulex, Dr. melanogaster, and P. humanus. We then calculated the average genetic distance among species for each block, using the JTT substitution matrix [48] and weighted by block length (see Methods). The unrooted dendrogram derived from a total of 94,146 aligned positions is shown in Figure 5. The $V$. destructor branch (0.42333) is substantially longer than the $I$. scapularis branch (0.26667) from their shared common ancestor, implying a high rate of amino-acid evolution

Table 5 Protein-encoding transposable elements in V. destructor

\begin{tabular}{llc}
\hline Class & Family & Number identified \\
\hline DNA & TcMar-Mariner & 6511 \\
\hline DNA & TcMar-Tc1 & 357 \\
\hline DNA & hAT & 58 \\
\hline DNA & TcMar-Fot1 & 27 \\
\hline DNA & MuDR & 12 \\
\hline Helitron & Helitron & 338 \\
\hline LINE & R1 & 981 \\
\hline LINE & L2 & 93 \\
\hline LINE & CR1 & 83 \\
\hline LINE & BovB & 47 \\
\hline LINE & Jockey & 28 \\
\hline LINE & L1 & 17 \\
\hline LTR & Gypsy & 914 \\
\hline LTR & Pao & 102 \\
\hline LTR & Copia & 74 \\
\hline LTR & Gypsy-Cigr & 31 \\
\hline Transpoble & Lentsidentfed with the protein-evel & \\
\hline
\end{tabular}

Transposable elements identified with the protein-level repeat masking mode of RepeatMasker [44]. Class abbreviations are DNA, type II DNA transposon; LINE, long interspersed nuclear element; LTR, long-terminal repeat retrotransposon. Family designations are those of RepBase [68]. in the Varroa lineage and/or a low rate of amino-acid evolution in the Ixodes lineage. Note that this distancebased approach does not require specifying a nucleotide substitution model or correcting for multiple substitutions; the branch lengths are approximately proportional to the product of the time since divergence and the branch-specific rate of molecular evolution (see [49] for a discussion). Furthermore, the branching order of these taxa are well-supported by independent data [50,51]. Of course, this result is averaged across many loci and does not necessarily represent the pattern of sequence divergence at any given gene. It remains to be seen whether other gene features, such as exon structure, have also evolved at a comparably divergent rates.

\section{Nucleotide polymorphism in $V$. destructor}

Life-history traits of $V$. destructor [5] that act to reduce genetic polymorphism within family lineages include male haploidy [25] and a predominance of full-sib mating. Genetic variation within a population can nonetheless be high in principle if populations are admixtures of distinct lineages. High-frequency polymorphisms, whether due to admixture or heterozygosity, can cause difficulties for shotgun assembly algorithms because they weaken the computational discrimination of allelic and non-allelic sequences. On the other hand, polymorphisms may be useful as genetic markers for population-genetic studies. It is therefore of interest to estimate levels of genetic polymorphism in the sequenced sample $(\sim 1,000$ mites drawn from three adjacent colonies). We used the program SWAP454 [52] to estimate the occurrence of moderate- to high-frequency SNPs, i.e. those present in reads at a minimum ratio of 0.1 to the assembly reference base. SNP calls also required a minimum of two reads with the alternative base, but did not require reads in both directions. Polymorphisms meeting these parameters occurred at a rate of $6.2 \times 10^{-5}$ per base pair. Given a median per-contig coverage of $5.0 \times$ in the final assembly (Table 1), our ability to detect low frequency polymorphisms is of course limited, but such polymorphisms contribute much less ambiguity to genome assembly.

To further investigate the potential for sequence polymorphism within a $V$. destructor population, we identified trinucleotide microsatellite loci in the genomic sequence and obtained amplification products for ten of these (see Methods). Consistent with our estimate of SNP frequency, we found no polymorphism at these loci in 65 individual mites collected from research apiaries at the USDA-ARS facility in Beltsville, Maryland, the source of the genome survey pool.

\section{Discussion}

$V$. destructor is considered the most damaging honeybee pest and has become widespread since its host shift 


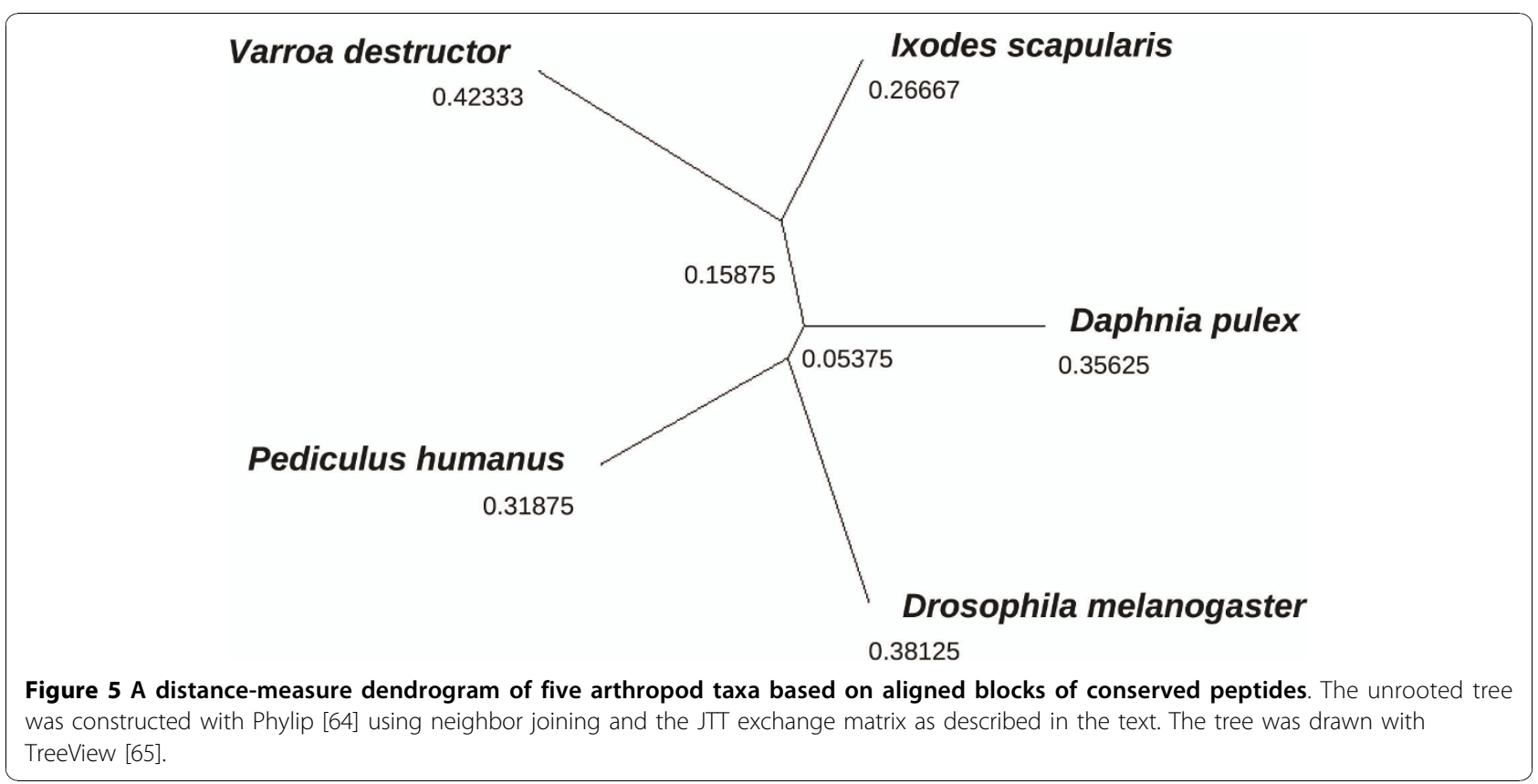

from A. cerana less than a century ago. Resistance to common acaricides has already appeared [53], and the development of new control strategies are hampered by our limited knowledge of the $V$. destructor - A. mellifera interaction, particularly at the genetic level. The present genome survey makes available a large number of genic sequences for analysis and manipulation by the community of researchers. The contigs we obtained from lowcoverage shotgun sequencing were short, as expected, such that few complete gene models are likely to be annotated from this data set. Nonetheless, our assembly enables the identification of genes of interest and the cloning of complete transcripts as they are needed. The assembly will also greatly assist the validation and annotation of transcriptome surveys and can support proteomic initiatives. We hope the resources provided here will aid investigators already tackling the problem of mite control with molecular methods as well as encourage the involvement of others.

Genetic approaches to the study of mite control are promising for a number of reasons. Successful reproduction of Varroa mites requires precise coordination with the care of honey bee brood and a sophisticated evasion of honey bee defences. Chemosensory genes are among those likely to play crucial roles in this process. At the phenotypic level, there is known variation among Varroa haplotype groups and species in their ability to successfully parasitize $A$. mellifera $[16,17]$, as well as known variation in the resistance of honey bee strains $[14,15,54,55]$. While Varroa mites are not tractable to controlled crosses, associative mapping of traits such as reproductive success on different hosts remains an attractive possibility, as is the mapping of resistance traits in honey bee. Resequencing efforts are needed to uncover genetic variation that can be exploited for these purposes. Those efforts would also contribute to a better understanding of the demographic history of $V$. destructor and to species relationships within the genus. Polymorphic markers within haplotype groups would aid investigations of the population biology of the species, particularly in light of the difficulty of observing or manipulating Varroa mites in their habitat. For example, estimates of outcrossing and migration might be relevant to the design of new mitigation strategies, particularly if the evolution of resistance traits is expected. While consistent with previous work [23] that found low genetic polymorphism within the predominant $V$. destructor lineage, our analysis nonetheless enables genome-scale mining of markers for population-genetic studies.

Our analysis of conserved peptide blocks showed a higher rate of protein evolution within the Varroa lineage relative to Ixodes. It remains to be clarified whether this level of sequence divergence is characteristic of mites or peculiar to the Varroa lineage. Similarly, whether this result correlates with divergence in other aspects of genome evolution, such as exon structure and regulatory features, will be an important question to pursue as annotations improve for both species. As genomic resources for $V$. destructor continue to improve, opportunities for evolutionary comparisons with other arthropods will be enriched. Such comparisons are of tremendous value because they can expose conserved elements that might otherwise elude detection by direct experiment, and they reveal the 
relative rates at which various classes of homologous sequence diverge. Varroa mites and others in the Parasitiformes comprise a lineage that diverged from ixodid ticks over 300 million years ago [56], while the chelicerates as a whole branched from the insects and crustacea 725 million years ago [57]. Consequently, as a representative of the Parasitiformes, Varroa provides a key evolutionary landmark for comparative studies across arthropods currently targeted for genomic analyses.

An accessory goal of genome projects targeting arthropod pests is the identification of novel microbes and viruses that may be relevant to the epidemiology of vectored diseases, or that lend themselves to biocontrol programs. A significant finding of this study was the discovery of an actinomycete bacterium that infects $V$. destructor at intermediate frequencies (albeit presumably at high titer given its abundance in the genome sequence) but apparently does not infect $A$. mellifera at appreciable levels. However, these findings are preliminary and await a more systematic survey of infection among mites and bees. Future research should also be directed toward isolating this bacterium and assessing the fitness consequences of infection. Further characterization of the putative baculovirus identified in this survey is similarly a priority.

This work contributes to the relatively small body of genomic studies to date that have applied next-generation sequencing to a complex eukaryotic genome phylogenetically distant from other reference genomes. As the costs and technical requirements for genome sequencing continue to decline, such studies will undoubtedly become commonplace. In many cases, the sequencing of a single genotype or inbred group will not be feasible, and there may also be a significant metagenomic contribution from associated microbes. While these factors introduce new challenges, our results underscore the utility of these methods for rapidly advancing the study of non-model organisms.

\section{Conclusions}

Our results have provided general tools for the research community and novel directions for investigating the biology and control of Varroa mites. Ongoing development of Varroa genomic resources will be a boon for comparative genomics of under-represented arthropods, and will further enhance the honey bee and its associated pathogens as a model system for studying hostpathogen interactions.

\section{Methods}

\section{Genome-size estimation}

Samples were prepared for flow cytometry as previously described [27]. For each replicate, the synganglion of a mature female $V$. destructor was placed along with the head of a mature female $D$. virilis into a $2 \mathrm{ml}$ tissue grinder (Kimble-Kontes) containing $1 \mathrm{ml}$ of cold Galbraith buffer, and stroked 15 times with the A pestle to release nuclei. The preparation was filtered through $20 \mu \mathrm{m}$ nylon and stained with prodidium iodide to a final concentration of $50 \mathrm{ppm}$. Stained samples were held on ice in the dark for 1-2 hr prior to analysis. The mean fluorescence of stained nuclei in replicate preparations of Varroa and D. virilis standard was quantified using a Coulter Epics Elite flow cytometer (Coulter Electronic), with excitation provided by a laser tuned at $488 \mathrm{~nm}$ and $25 \mathrm{~mW}$. PI fluorescence at $>615 \mathrm{~nm}$ was detected by a photomultiplier screened by a long pass filter. To ensure that scoring included only intact nuclei free from cytoplasmic tags, counting was activated by red fluorescence (discrimination), and only (gated) nuclei with low forward and side scatter were included in the analysis. The positions of sample peaks relative to the $D$. virilis peak were verified by running samples without a standard. DNA content was determined from co-preparations as the ratio of the $2 \mathrm{C}$ Varroa peak to the $2 \mathrm{C} \mathrm{D}$. virilis peak times the $1 C$ genome size of $D$. virilis (333 Mb, after [58]).

\section{Sample preparation and sequencing}

$V$. destructor mites were collected on two occasions for sequencing from infested colonies of the USDA-ARS Bee Research Laboratory apiaries in Beltsville, MD, USA in October, 2008. For each collection, 300 bees were placed into a 0.5 liter glass jar containing $40 \mathrm{~g}$ confectioner's sugar. The sugar and bees were thoroughly mixed by shaking the jar for $30 \mathrm{~s}$. The sugar and phoretic mites were then separated from their bee hosts by shaking the jar contents through a $1 \mathrm{~mm}$ wire mesh placed at the jar opening. Mites were shaken into a small water bath, which was then poured through a cheesecloth filter and rinsed twice with sterile water to remove residual sugar. Live mites were then picked onto sterile tissue paper and frozen at $-80^{\circ} \mathrm{C}$ until nucleic acid extraction.

To obtain sufficient high-quality DNA for six pyrosequencing runs, three separate DNA extractions were made from the collected mites. DNA from one sample of $\sim 400$ mites was extracted with DNAzol (Invitrogen) following the manufacturer's instructions. A second sample of $\sim 400$ mites was homogenized in $800 \mu \mathrm{l}$ proteinase $\mathrm{K}$ buffer $(10 \mathrm{mM} \mathrm{NaCl}, 10 \mathrm{mM}$ Tris, $50 \mathrm{mM}$ ethylenediamenetetracetic acid (EDTA), and $10 \mu \mathrm{g} / \mathrm{ul}$ proteinase $\mathrm{K}$ ) and incubated $60 \mathrm{~min}$ at $55^{\circ} \mathrm{C}$, vortexing every $20 \mathrm{~min}$. Afterwards, $180 \mu \mathrm{l}$ of $8 \mathrm{M}$ potassium acetate was added and the sample incubated on ice for 30 min. After high-speed centrifugation, DNA was precipitated from the supernatant with ethanol and re-suspended in distilled, deionized water. A third sample of 
$\sim 200$ mites was homogenized in $500 \mu$ l hexadecyltrimethylammonuim bromide (CTAB) buffer $(100 \mathrm{mM}$ Tris- $\mathrm{HCl}$ at $\mathrm{pH} 8.0,20 \mathrm{mM}$ EDTA, 1.4 $\mathrm{M} \mathrm{NaCl}, 2 \%$ $\mathrm{CTAB}$, and $0.2 \% \beta$-mercaptoethanol) and incubated $60 \mathrm{~min}$ at $65^{\circ} \mathrm{C}$, vortexing every $20 \mathrm{~min}$. An equal volume of 24:1 chloroform:isoamyl alcohol was then added and the sample centrifuged at high speed. DNA was precipitated from the supernatant with isopropanol and re-suspended in distilled, deionized water. For all extractions, DNA concentration and quality were evaluated with a Nanodrop ND-8000 spectrophotometer and were found to be comparable. DNA quality was also checked by gel electrophoresis.

Pyrosequencing was performed at the Institute for Genome Sciences, University of Maryland School of Medicine, on a Genome Sequencer FLX instrument (454 LifeSciences) using GS-FLX titanium reagents. DNA was prepared for emulsion PCR according to the manufacturer's protocols.

\section{Assembly and analysis}

Contigs were assembled with the CABOG package of Celera Assembler version 5.2 [31]. The sequences were assembled iteratively, adjusting the assumed error rate incrementally between $0 \%$ and $6 \%$. The assembly selected for analysis used a $1.5 \%$ error rate because this value maximized the length of the longest contig (18.7 $\mathrm{Kbp})$. The weighted median N50 contig size was relatively stable across iterations at $\sim 2.1 \mathrm{Kbp}$, meaning that half of the assembled bases were consistently contained in contigs of this size or larger across the different assemblies.

Contigs were screened to identify sequences of organisms that were considered potential contaminants a priori. For example, a number of contigs were found to be nearly identical to the honey bee reference genome [59]. These fragments included low-copy genic sequences as well as ribosomal, nongenic, and mitochondrial sequence. PCR primers specific to $A$. mellifera sequences amplified genomic DNA extracted from adult female mites but not from embryos (data not shown), implying that the source of $A$. mellifera contamination is bee hemolymph consumed by mites. In contrast, searches against the genome sequences [21] of chalkbrood (Ascosphaera apis), a fungal pathogen of honey bees, and American foulbrood (Paenibacillus larvae), a bacterial pathogen, did not reveal the presence of these spore-dispersed microbes in the sample.

All contigs were also screened for general bacterial contamination by searching ORFs of 90 codons or more against the RAST [60] seed database of bacterial sequences. ORFs were identified with the getorf program of the EMBOSS package [61]. ORFs with significant matches to the RAST database were then searched by
BLASTP against the full GenBank nr database to determine the most closely matching organism. Candidate microbial sequences are summarized in Table 6. As expected (see Results), matches to the phylum Actinobacteria are the vast majority. Among the small number of BLASTP matches to other bacterial groups, the genera Burkholderia ( $\beta$-proteobacteria) and Pseudomonas ( $\gamma$-proteobacteria) were the most represented taxa.

Because many organisms show distinct patterns of codon usage [62], we compared codon usage for ORFs from unfiltered contigs (putatively $V$. destructor) with those from putatively bacterial contigs. Only ORFs with BLAST-supported homology to GenBank sequences were used for this comparison. We used the program INCA [63] to plot the codon-usage statistic 'B' of [62] as a function of third-position $\mathrm{G}+\mathrm{C}$ (GC3) content (Additional file 6). The value of $B$ for a given ORF is a measure of how similar its codon usage is to the overall codon usage in the data set. GC3 is considered here because third positions are much less constrained by protein function than first and second positions, and thus more indicative of background composition biases. The distinct patterns observed for the two groups of ORFs provide complementary evidence that these sequences do in fact derive from different organisms. The plot also shows that a few ORFs from contigs considered to be Varroa by our filtering methods may in fact be bacterial in nature and merit further evaluation. Of course, BLAST-supported ORFs are only proxies for transcripts and thus individual points may be highly inaccurate. In general, however, genic sequences that are putatively from $V$. destructor have a cohesive pattern of codon usage that can be distinguished form at least some bacterial contaminants, regardless of detectable homology.

To confirm the presence in mites of the actinomycete bacterium and DNA virus identified in the assembly, individual eggs, nymphs, female adults, and male adults were

Table 6 Distribution of contigs that were designated bacterial by BLAST analysis, sorted by phylum

\begin{tabular}{ll}
\hline Phylum & Number of contigs \\
\hline Actinomycete & 1035 \\
\hline$\alpha$-proteobacteria & 10 \\
\hline Aquificae & 1 \\
\hline Bacteroides & 2 \\
\hline$\beta$-proteobacteria & 13 \\
\hline Cyanobacteria & 3 \\
\hline$\delta$-proteobacteria & 3 \\
\hline Euryarachaeota & 1 \\
\hline Firmicutes & 4 \\
\hline $\boldsymbol{\gamma}$-proteobacteria & 12 \\
\hline
\end{tabular}


collected from parasitized honey bee pupae. DNA for PCR was extracted from individual samples by grinding them in $200 \mu \mathrm{l}$ of $5 \%$ Chelex-100 solution (Bio-Rad), incubating at $65^{\circ} \mathrm{C}$ for $30 \mathrm{~min}$, pelleting the mixture by high-speed centrifugation, and taking a 1:10 dilution in water of the resulting supernatant. Primers for the putative actinomycete TIF3 locus were CCGATCTCGACCTTGTGGAA (forward) and CTCGGAACATGATCGTCACC (reverse), and for the ABC locus were GAGGTCCTCGTCTCCGAATG (forward) and CGATGTCCTGGATCCTCTGG (reverse). The amplified TIF3 product was confirmed by Sanger sequencing (GenBank:GU365869). Primers designed to amplify the putative Baculovirus targeted a ribonucleotide reductase small subunit gene (forward ACGAACGACTATCTAGCCATGAAC and reverse GTCCGTTTCGGAGTGCATGAC) and a thymidylate synthase gene (forward CGCATGTACCAACAACTCGTAC and reverse CACAGTTGGTGTAGCGCAGT). The identities of these products were also confirmed by Sanger sequencing (GenBank:GU980896 and GenBank: GU980897, respectively). All PCR reactions were performed using standard reagents and thermocycler protocols, with an annealing temperature of $54^{\circ} \mathrm{C}$.

To identify conserved peptide blocks, we first identified $V$. destructor ORFs that were reciprocal best BLASTP matches with I. scapularis predicted peptides. These were then used to identify the closest homologs in Da. pulex, Dr. melanogaster, and P. humanus. Sequences were aligned by ClustalW and then trimmed to include only blocks of well conserved, unambiguously aligned sequence for which we could have reasonable confidence of orthology. Genetic-distance matrices were calculated for each block with the protdist program of the PHYLIP package [64], weighted by alignment length and summed, then normalized to a maximum distance of one. Unrooted dendrograms were constructed with the fitch and neighbor programs of the PHYLIP package, giving virtually identical branch lengths; the neighbor-joining dendrogram is shown in Figure 5.

Microsatellite loci used to assess polymorphism levels in $V$. destructor are characterized in Additional file 7. PCR amplifications consisted of $1 \mathrm{U}$ Taq DNA polymerase with appropriate buffer, $1 \mathrm{mM}$ dNTP, $2 \mathrm{mM} \mathrm{MgCl}$, $0.2 \mu \mathrm{M}$ of each forward and reverse primer in a final reaction volume of $5 \mu \mathrm{l}$. Fluorescently labeled primers were mixed with unlabeled primers at a 12:20 ratio. Thermocycling was performed as follows: $96^{\circ} \mathrm{C}$ for 2 min., then 3 cycles of $96^{\circ} \mathrm{C}$ for $30 \mathrm{sec}$, $60^{\circ} \mathrm{C}$ for $30 \mathrm{sec}$. $\left(-1^{\circ} \mathrm{C} / \mathrm{Cycle}\right), 65^{\circ} \mathrm{C}$ for $1 \mathrm{~min}$., followed by 35 cycles of $96^{\circ} \mathrm{C}$ for 30 sec., $56^{\circ} \mathrm{C}$ for 30 sec., $65^{\circ} \mathrm{C}$ for $1 \mathrm{~min}$, and a final extension at $65^{\circ} \mathrm{C}$ for $2 \mathrm{~min}$. PCR products were diluted $1: 20$ and $1 \mu \mathrm{l}$ of this dilution was added to 10 $\mu \mathrm{L}$ formamide containing the LIZ size standard. Products were analyzed by capillary electrophoresis using an Applied Biosystems 3730XL instrument. Allele sizes were scored using ABI GeneMapper version 3.7 (Applied Biosystems).

\section{Additional material}

\begin{abstract}
Additional file 1: Annotation statistics for filtered high $\mathrm{G}+\mathrm{C}$ contigs Annotation statistics derived from the BLAST2GO annotation tool [34]. A. Distribution of BLASTX hits $\left(E \leq 10^{-10}\right)$ by organism. Note that the "Others" category is typically the most abundant in this type of analysis because of the wide taxonomic distributions of many conserved proteins. B. Distribution of BLASTX hits by sequence similarity score. C. Distribution of BLASTX hits by expectation.
\end{abstract}

Additional file 2: Contigs identified as deriving from a novel virus of the Baculoviridae. Fasta-formatted contigs were classified as described in text. Also included are the methionine-initiated ORFs of 90 codons or more that are referenced in Table 3.

Additional file 3: BLAST-annotated Varroa contigs. Spreadsheet of Varroa destructor genomic contigs with significant similarity to the GenBank nr database by BLAST search.

Additional file 4: ORFs with Pfam domains. Spreadsheet of significant Pfam domains within ORFs having BLASTP-detected similarity to GenBank sequences.

Additional file 5: ORFs referenced in Additional file 3and Additonal file 4. Fasta-formatted ORFs from $V$. destructor contigs that had significant sequence similarity to database sequences.

Additional file 6: Comparison of ORF codon usage for contigs assigned as either Varroa destructor or bacterial in origin. Scatterplot comparing $\mathrm{G}+\mathrm{C}$ content and codon usage of ORFs from contigs assigned as either Varroa destructor or bacterial. The $\mathrm{X}$-axis value is third position $\mathrm{G}+\mathrm{C}$ and the $\mathrm{Y}$-axis value is the codon usage statistic B [62], which as used here is a measure of the difference in codon usage between each subgroup of ORFs relative to the whole. The possible range of values for $\mathrm{B}$ is 0 to 2, with larger values corresponding to greater divergence in codon frequencies. A. Residual contigs after filtering, which are assumed to all derive from V. destructor. B. Contigs filtered because they have a higher BLAST score to bacterial sequences than to eukaryotic sequences. The two groups of contigs have distinct patterns of codon usage and nucleotide composition.

Additional file 7: Microsatellite loci used in Varroa destructor polymorphism survey. Table lists contig containing the microsatellite locus, forward and reverse primer sequences, expected product size based on the reference contig, and the $5^{\prime}$ start coordinate on the contig for the forward primer.

\section{Acknowledgements}

Financial support for this survey and an ongoing full genome sequencing project provided by USDA-ARS and the USDA National Institute of Food and Agriculture (grant 2009-05254 to JDE, GH, CE and LB). Additional support was provided by NIH grant R01-LM006845 and NSF grant NSF IIS-084494 to the University of Maryland (Steven Salzberg) and the University of Florida Department of Agriculture (JDE). We thank Antoinette Betschart and Kevin Hackett, USDA-ARS, for logistical support, Dawn Lopez for technical support, and the Institute for Genomic Sciences, University of Maryland, Baltimore, for sequencing. The helpful critique of three anonymous reviewers greatly improved the manuscript.

\section{Author details}

${ }^{1}$ USDA-ARS, Bee Research Laboratory, 10300 Baltimore Ave., Beltsville, MD 20705 USA. ${ }^{2}$ Center for Bioinformatics and Computational Biology, University of Maryland, College Park, MD 20742 USA. ³ Department of Entomology, Texas A\&M University, College Station, TX 77843 USA. ${ }^{4}$ Department of Entomology, Purdue University, West Lafayette, IN 47907 USA. 5 USDA-ARS, Honey Bee Research Laboratory, 1157 Ben Hur Rd., Baton Rouge, LA 70820 USA. 'Department of Biology, Georgetown University, 37th and O Streets, 
NW, Washington, DC 20057 USA. ${ }^{7}$ CSIRO Entomology, Black Mountain Laboratories, Clunies Ross Street, Black Mountain ACT 2601, Australia. ${ }^{8}$ Department of Entomology, Penn State University, University Park, PA 16802 USA.

\section{Authors' contributions}

RSC led the bioinformatic analyses and writing. JDE designed and coordinated the project and helped with analyses and writing. MCS generated the genome assembly. JSS performed the genome size estimation. YPC and JSP participated in project design and the collection of biological materials. GH, LB, CE, DA, and CMG aided in data analysis and manuscript preparation. All authors read and approved the final manuscript.

Received: 18 March 2010 Accepted: 25 October 2010

Published: 25 October 2010

\section{References}

1. Morse RA, Calderone NW: The value of honey bees as pollinators of U.S. crops in 2000. Bee Culture 2000, 128:1-15.

2. Gallai N, Salles JM, Settele J, Vaissiere BE: Economic valuation of the vulnerability of world agriculture confronted with pollinator decline. Ecological Economics 2009, 68:810-821.

3. Aizen MA, Harder LD: The global stock of domesticated honey bees is growing slower than agricultural demand for pollination. Current Biology 2009, 19:915-918.

4. Cox-Foster DL, Conlan S, Holmes EC, Palacios G, Evans JD, Moran NA, Quan PL, Briese T, Hornig M, Geiser DM, et al: A metagenomic survey of microbes in honey bee colony collapse disorder. Science 2007, 318:283-287.

5. Rosenkranz $P$, Aumeier $P$, Ziegelmann B: Biology and control of Varroa destructor. J Invertebr Pathol 103(Suppl 1):S96-119.

6. Anderson DL, Trueman JWH: Varroa jacobsoni (Acari: Varroidae) is more than one species. Experimental and Applied Acarology 2000, 24:165-189.

7. Johnson RM, Evans JD, Robinson GE, Berenbaum MR: Changes in transcript abundance relating to colony collapse disorder in honey bees (Apis mellifera). Proc Natl Acad Sci USA 2009, 106:14790-14795.

8. Highfield AC, El Nagar A, Mackinder LC, Noel LM, Hall MJ, Martin SJ, Schroeder DC: Deformed wing virus implicated in overwintering honeybee colony losses. Appl Environ Microbiol 2009, 75:7212-7220.

9. Yang X, Cox-Foster D: Effects of parasitization by Varroa destructor on survivorship and physiological traits of Apis mellifera in correlation with viral incidence and microbial challenge. Parasitology 2007, 134:405-412.

10. Boecking $\mathrm{O}$, Genersch E: Varroosis - The ongoing crisis in bee keeping. Journal fur Verbraucherschutz und Lebensmittelsicherheit 2008, 3:221-228.

11. Sammataro D, Gerson U, Needham G: Parasitic mites of honey bees: life history, implications, and impact. Annu Rev Entomol 2000, 45:519-548.

12. Kuenen LPS, Calderone NW: Transfers of Varroa mites from newly emerged bees: Preferences for age- and function-specific adult bees (Hymenoptera: Apidae). Journal of Insect Behavior 1997, 10:213-228.

13. Kraus B: Factors influencing host choice of the honey bee parasite Varroa jacobsoni Oud. Experimental and Applied Acarology 1994, 18:435-443.

14. De Guzman LI, Rinderer TE, Frake AM: Comparative reproduction of Varroa destructor in different types of Russian and Italian honey bee combs. Experimental and Applied Acarology 2008, 44:227-238.

15. Rinderer TE, De Guzman LI, Delatte GT, Harper C: An evaluation of ARS Russian honey bees in combination with other methods for the control of Varroa mites. American Bee Journal 2003, 143:410-413.

16. Anderson DL: Non-reproduction of Varroa jacobsoni in Apis mellifera colonies in Papua New Guinea and Indonesia. Apidologie 1994, 25:412-421.

17. Anderson DL, Fuchs S: Two genetically distinct populations of Varroa jacobsoni with contrasting reproductive abilities on Apis mellifera. Journal of Apicultural Research 1998, 37:69-78.

18. Navajas M, Anderson DL, De Guzman LI, Huang ZY, Clement J, Zhou T, Le Conte Y: New Asian types of Varroa destructor: a potential new threat for world apiculture. Apidologie 2010.

19. NCBI Genome Project ID 33467. [http://www.ncbi.nlm.nih.gov/genomepri? term $=$ Varroa\%20destructor].

20. Cornman RS, Chen YP, Schatz MC, Street C, Zhao Y, Desany B, Egholm M, Hutchison S, Pettis JS, Lipkin WI, et al: Genomic analyses of the microsporidian Nosema ceranae, an emergent pathogen of honey bees. PLoS Pathog 2009, 5:e1000466.

21. Qin X, Evans JD, Aronstein KA, Murray KD, Weinstock GM: Genome sequences of the honey bee pathogens Paenibacillus larvae and Ascosphaera apis. Insect Molecular Biology 2006, 15:715-718.

22. De Guzman LI, Rinderer TE, Stelzer JA: Occurrence of two genotypes of Varroa jacobsoni oud. in North America. Apidologie 1999, 30:31-36.

23. Solignac M, Cornuet J-M, Vautrin D, Le Conte Y, Anderson D, Evans J, CrosArteil S, Navajas M: The invasive Korea and Japan types of Varroa destructor, ectoparasitic mites of the Western honeybee (Apis mellifera), are two partly isolated clones. Proceedings of the Royal Society - Biological Sciences (Series B) 2005, 272:411-419.

24. Anderson DL: Variation in the parasitic bee mite Varroa jacobsoniOud. Apidologie 2000, 31:281-292.

25. Steiner J, Grasas Pompolo S, Takahashi CS, Gonsalves LS: Cytogenetics of the acarid Varroa jacobsoni. Brazilian Journal of Genetics 1982, 4:841-844.

26. Pagel Van Zee J, Geraci NS, Guerrero FD, Wikel SK, Stuart JJ, Nene VM, Hill CA: Tick genomics: the Ixodes genome project and beyond. Int J Parasitol 2007, 37:1297-1305.

27. Geraci NS, Johnston JS, Robinson JP, Wikel SK, Hill CA: Variation in genome size of argasid and ixodid ticks. Insect Biochemistry and Molecular Biology 2007, 37:399-408.

28. Grbic M, Khila A, Lee KZ, Bjelica A, Grbic V, Whistlecraft J, Verdon L, Navajas M, Nagy L: Mity model: Tetranychus urticae, a candidate for chelicerate model organism. Bioessays 2007, 29:489-496.

29. wFleaBase. [http://wfleabase.org/].

30. The International Aphid Genomics Consortium: Genome sequence of the pea aphid Acyrthosiphon pisum. PLoS Biol 2010, 8:e1000313.

31. Miller JR, Delcher AL, Koren S, Venter E, Walenz BP, Brownley A, Johnson J, Li K, Mobarry C, Sutton G: Aggressive assembly of pyrosequencing reads with mates. Bioinformatics 2008, 24:2818-2824.

32. Lander $E S$, Waterman MS: Genomic mapping by fingerprinting random clones: a mathematical analysis. Genomics 1988, 2:231-329.

33. Tyson GW, Chapman J, Hugenholtz P, Allen EE, Ram RJ, Richardson PM, Solovyev W, Rubin EM, Rokhsar DS, Banfield JF: Community structure and metabolism through reconstruction of microbial genomes from the environment. Nature 2004, 428:37-43.

34. Gotz S, Garcia-Gomez JM, Terol J, Williams TD, Nagaraj SH, Nueda MJ, Robles M, Talon M, Dopazo J, Conesa A: High-throughput functional annotation and data mining with the Blast2GO suite. Nucleic Acids Res 2008, 36:3420-3435.

35. Klepzig KD, Adams AS, Handelsman J, Raffa KF: Symbioses: a key driver of insect physiological processes, ecological interactions, evolutionary diversification, and impacts on humans. Environ Entomol 2009, 38:67-77.

36. Finn RD, Tate J, Mistry J, Coggill PC, Sammut SJ, Hotz HR, Ceric G, Forslund K, Eddy SR, Sonnhammer EL, et al: The Pfam protein families database. Nucleic Acids Res 2008, 36:D281-288.

37. Baculovirus Molecular Biology. [http://www.ncbi.nlm.nih.gov/bookshelf/br. fcgi?book=bacvir].

38. Rosell G, Quero C, Coll J, Guerrero A: Biorational insecticides in pest management. Journal of Pesticide Science 2008, 33:103-121.

39. Herniou EA, Olszewski JA, Cory JS, O'Reilly DR: The genome sequence and evolution of baculoviruses. Annu Rev Entomol 2003, 48:211-234.

40. Ogata H, Goto S, Sato K, Fujibuchi W, Bono H, Kanehisa M: KEGG: Kyoto Encyclopedia of Genes and Genomes. Nucleic Acids Res 1999, 27:29-34.

41. Vectorbase. [http://www.vectorbase.org].

42. Parra G, Bradnam K, Ning Z, Keane T, Korf I: Assessing the gene space in draft genomes. Nucleic Acids Res 2009, 37:289-297.

43. HMMER3: a new generation of sequence homology search software. [http://hmmer.janelia.org].

44. RepeatMasker Open-3.0. [http://www.repeatmasker.org].

45. Volff JN: Turning junk into gold: domestication of transposable elements and the creation of new genes in eukaryotes. Bioessays 2006, 28:913-922.

46. Atkinson PW, Pinkerton AC, O'Brochta DA: Genetic transformation systems in insects. Annu Rev Entomol 2001, 46:317-346.

47. Jeyaprakash A, Hoy MA: First divergence time estimate of spiders, scorpions, mites and ticks (subphylum: Chelicerata) inferred from mitochondrial phylogeny. Exp Appl Acarol 2009, 47:1-18.

48. Jones DT, Taylor WR, Thornton JM: The rapid generation of mutation data matrices from protein sequences. Computer Applications in the Biosciences 1992, 8:275-282. 
49. Felsenstein J: Inferring phylogenies. Sunderland, Mass.: Sinauer 2004.

50. Regier JC, Shultz JW, Zwick A, Hussey A, Ball B, Wetzer R, Martin JW, Cunningham CW: Arthropod relationships revealed by phylogenomic analysis of nuclear protein-coding sequences. Nature 463:1079-1083.

51. Wheeler WC, Whiting M, Wheeler QD, Carpenter JM: The phylogeny of the extant hexapod orders. Cladistics 2005, 17:113-169.

52. Brockman W, Alvarez P, Young S, Garber M, Giannoukos G, Lee WL, Russ C, Lander ES, Nusbaum C, Jaffe DB: Quality scores and SNP detection in sequencing-by-synthesis systems. Genome Res 2008, 18:763-770.

53. Pettis JS: A scientific note on Varroa destructor resistance to coumaphos in the United States. Apidologie 2004, 35:91-92.

54. Guzman-Novoa E, Vandame R, Arechavaleta ME: Susceptibility of European and Africanized honey bees (Apis mellifera L.) to Varroa jacobsoni Oud. in Mexico. Apidologie 1999, 30:173-182.

55. Moretto G, Mello LJd Jr: Varroa jacobsoni infestation of adult Africanized and Italian honey bees (Apis mellifera) in mixed colonies in Brazil. Genetics and Molecular Biology 1999, 22:321-323.

56. Jeyaprakash A, Hoy MA: First divergence time estimate of spiders, scorpions, mites and ticks (subphylum: Chelicerata) inferred from mitochondrial phylogeny. Experimental and Applied Acarology 2009, 47:1-18.

57. Pisani D, Poling LL, Lyons-Weiler M, Hedges SB: The colonization of land by animals: molecular phylogeny and divergence times among arthropods. BMC Biology 2004, 2:1.

58. Gregory TR, Johnston JS: Genome size diversity in the family Drosophilidae. Heredity 2008, 101:228-238.

59. Honey Bee Genome Sequencing Consortium: Insights into social insects from the genome of the honeybee Apis mellifera. Nature 2006, 443:931-949.

60. Aziz RK, Bartels D, Best AA, Dejongh M, Disz T, Edwards RA, Formsma K, Gerdes S, Glass EM, Kubal M, et al: The RAST Server: rapid annotations using subsystems technology. BMC Genomics 2008, 9:75.

61. Rice P, Longden I, Bleasby A: EMBOSS: the European Molecular Biology Open Software Suite. Trends Genet 2000, 16:276-277.

62. Karlin S, Mrazek J, Campbell AM: Codon usages in different gene classes of the Escherichia coli genome. Mol Microbiol 1998, 29:1341-1355.

63. Supek F, Vlahovicek K: INCA: synonymous codon usage analysis and clustering by means of self-organizing map. Bioinformatics 2004 20:2329-2330

64. Felsenstein J: PHYLIP - Phylogeny Inference Package (Version 3.2). Cladistics 1989, 5:164-166.

65. Page RD: TreeView: an application to display phylogenetic trees on personal computers. Comput Appl Biosci 1996, 12:357-358.

66. Interpro. [http://www.ebi.ac.uk/interpro/].

67. Uniprot. [http://www.uniprot.org].

68. Jurka J, Kapitonov W, Pavlicek A, Klonowski P, Kohany O, Walichiewicz J: Repbase Update, a database of eukaryotic repetitive elements. Cytogenet Genome Res 2005, 110:462-467.

doi:10.1186/1471-2164-11-602

Cite this article as: Cornman et al:: Genomic survey of the ectoparasitic mite Varroa destructor, a major pest of the honey bee Apis mellifera. BMC Genomics 2010 11:602.

\section{Submit your next manuscript to BioMed Central and take full advantage of:}

- Convenient online submission

- Thorough peer review

- No space constraints or color figure charges

- Immediate publication on acceptance

- Inclusion in PubMed, CAS, Scopus and Google Scholar

- Research which is freely available for redistribution

Submit your manuscript at www.biomedcentral.com/submit
Biomed Central 